\title{
A Framework of Resilience for Peer-to-Peer Accommodation Hosts Under COVID-19
}

\author{
Yu-Hua $\mathrm{Xu}^{1}$, Shihan (David) $\mathrm{Ma}^{2(\bowtie)}$, and Xin-Yue $\mathrm{Li}^{2}$ \\ 1 Arizona State University, HNU-ASU International Tourism College, \\ Haikou, People's Republic of China \\ 2 School of Management, Zhejiang University, \\ Hangzhou, People's Republic of China \\ mashihan@zju.edu.cn
}

\begin{abstract}
The pandemic has hit the tourism industry in various ways. P2P accommodation (P2PA) is one of most disrupted sectors. Different types of P2PA hosts are confronting different levels of challenges. From an angle of social equity, the study adopted a resilience model to examine the resilience of P2PA hosts' business during the first COVID outbreak in Florida, USA. Statistical results show P2PA hosts' business resilience negatively associates with their housing liability and hosting experience. Social superiority in owning more assets can be a defect in coping with COVID crisis. P2PA operators need to maintain an appropriate level of financial flexibility when faced with the threat of COVID outbreaks. We suggest the government and industrial organizations to distinguish the types of P2PA operators when carrying out rescue plans for the industry.
\end{abstract}

Keywords: P2P lodging $\cdot$ Financial resilience $\cdot$ Social equity $\cdot$ Pandemic recovery

\section{Introduction}

With the ongoing COVID-19 pandemic and the emergence of new variants of the virus upgrading the unpredictability of the global lodging market, recovering from the constant outbreaks and strengthen financial resilience of accommodation business has become one of the most urgent topics in hospitality industry.

Compared with corporational hotel businesses, small lodging establishments like Peer-to-Peer accommodations (P2PA) experiences a higher level of operational vulnerabilities and business fragilities [1]. While traditional "sharing economy" assumes the sharing of personal idle resources for non-essentially profit purpose, the burgeoning professional P2PA hosts own multiple properties and operate their business in a similar way as full-time hoteliers. Who are more resilient and adaptive in the pandemic disturbing? These professional players fully dependent on accommodation investment for living, or those with only individual listed property? Given the potential government subsidies for small establishments in the hospitality industry, there is an urgent need to understand the mechanism of resilience and examine the resilience status of different types of hosts in the P2PA industry. 
The study is first to testify to an adapted resilience model to examine financial resilience in P2PA industry; Second, we aim to examine the level of resilience among different types of P2PA hosts based on our proposed model.

\section{Theoretical Background}

Resilience was defined as the ability of a system to return to equilibrium after a shock [2]. Despite the variability in definitions of social/human-related resilience, many address the interplay between social vulnerability and the adaptive ability, and how the human network reorganizes and transforms during disturbances and shocks. Briguglio et al. [3] proposed a risk model which distinguished the character of vulnerability and resilience in an economic context, where vulnerability was considered as an inherent factor, while resilience played as a nurtured factor that can ease the risk. The subtraction between vulnerability and resilience equals the risk. This static model refers "risk" as the endogenous odds of being exposed to external shocks, rather than an external factor that is independent from the entity under observation. As a result, it is difficult to operationalize the "risk" factor and evaluate its effect in empirical cases.

Martin [4] proposed a spatial-economic resilience model to describe socioeconomic system's adaptive power to regional economic hysteresis. The conceptual model put that how much a system can absorb depends on its intrinsic vulnerability and resilience features. Based on Briguglio's and Martin's work, we proposed our framework to measure resilience as in Eq. 1:

$$
\text { Resilience }=\text { Adaptability }-(\text { Vulnerability }+ \text { Shock })
$$

Three research questions were consequently developed from the research goals:

Question 1: How could the pandemic shock affect the resilience of P2PA business? Question 2: How could adaptability affect the resilience of P2PA business?

Question 3: How could vulnerability affect the resilience of P2PA business?

The concept of social equity has been widely used in tourism and economy domain [5], especially to explain the dynamics in the interactions between hosts and tourists [6]. Yet another possible dyadic inequity, the imbalance and contradiction between smaller operators and large asset owners, is equally noteworthy but has been largely neglected. During the pandemic, small operators may have suffered disproportionate challenge because of their financial inelasticity [1]. The supply side of hospitality industry has long been dominated by perspectives of industrial development, and there is an urgent call for a scrutiny of the possible imbalance among different scales of P2P accommodation hosts.

Based on the discussion of social equity, the last research question was developed:

Question 4: Do hosts with social superiority possess higher business resilience? 


\section{Research Design}

\subsection{Conceptual Framework}

We proposed a model to measure the financial resilience of $\mathrm{P} 2 \mathrm{P}$ accommodation during the pandemic (Fig. 1) based on the abovementioned resilience framework.

The severity of the COVID represents the level of external shock, which is operationalized as the number of COVID-19 infected cases. We used both Overall Shock (OS) (monthly new reported case number of Florida) and Local Shock $(\boldsymbol{L S})$ (reported cases on county level, weighted by the room scale of the property situating within the county) for measurement.

Adaptability is represented by a series of variables regarding host capability, business scale/feature and operational experience, including Host Experience (HE) (the length of a host's experience in P2PA business), Property Scale (PS) (total number of operating properties under one host), Room Scale (RS) (total number of available bedrooms under one host) and Business Level (BL) (average room rate from January 2008 to February 2020, indicating the targeted market of a host's P2PA properties).

Vulnerability is gauged by the financial liability in maintaining the properties. Maintenance Cost (MC) is the monthly housing expense including utilities, property tax, and mortgage; Housing Burden $(\boldsymbol{H B})$ is the ratio calculated by the MC over regional household income.

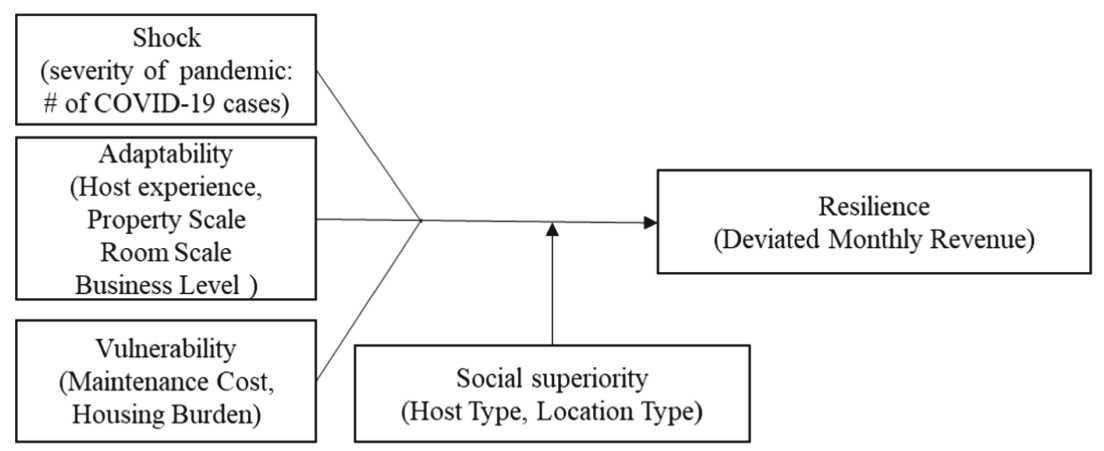

Fig. 1. Conceptual model

The Dependent Variable (DV), resilience, is represented by Deviated Monthly Revenue (DMR). It is calculated by the difference between the monthly revenue yearon-year, where month ranges from March 2020 to September 2020. A positive DMR indicates vigorous performance and strong resilience of the business hosts, and vice versa.

Finally, we introduce two Control Variables (CVs) to represent the construct Social Superiority. Host Type (HT) reflects hosts' individual social superiority based on their owned properties scales. HT is an ordinal variable with "Single" represents hosts with one property, "Small" for two to three properties, "Medium" for four to five properties), 
and "Large" for over five properties. Location Type (LT) reflects the social superiority of a host' neighborhood. It was calculated by the median housing value of the community where the properties are located.

\subsection{Data Preparation and Preprocessing}

We took the State of Florida as the study site for the research. The primary data was purchased from AirDNA (www.airdna.co). The time span of the data ranged from early 2008 to September 2020. The reported COVID case data was retrieved from the New York Times (NYT) Coronavirus Data in the United States. The financial cost data for vulnerability-dimension were obtained from American Community Survey (ACS) data. The NYT and ACS datasets were later integrated to the primary dataset by either zipcode or county labels.

The completed dataset was structured by monthly entries of host performance during the COVID pandemic. We finally collected 138,138 entries from 43,935 hosts after data preprocessing. During the observed period, 4,550 hosts shutdown their business and the remaining 39,385 survived at the end of September 2020. We further removed the data points with missing values and outliers, retaining a final dataset of 112,597 monthly entries from 29,114 hosts for analysis.

\section{Preliminary Results and Conclusion}

The conceptual model was tested with OLS linear regression with a decent explanation power $\left(\mathrm{R}^{2}=0.24\right)$ (see overall model in Table 1$)$.

Both overall shock (OS) and local shock (LS) are significant factors influencing host resilience. OS (standardized beta $=-0.46, \mathrm{p}<0.01$ ) has an overwhelmingly negative impact, arguably the strongest, on revenue performance. This indicates that the majority of the P2PA business suffer from the external shock of the pandemic. Interestingly, LS has a slight positive effect (beta $=0.03$ ), albeit largely overshadowed by the powerful negativity from OS. The plausible explanation is that the hotspots of the first peak of the pandemic in Florida concentrates on those top tier destinations with crowds of visitors and likely better revenue performance, yet inevitably causing a higher number of infected cases at the local level. Regardless of the positive effect from LS on DV, the overall travel flows to Florida have shrunk significantly, as the OS has devastatingly influenced tourists' willingness to travel and play a more crucial role in the performance of P2PA industry during the pandemic.

Adaptability variables like host experience $(\mathrm{HE})$ (beta $=-0.08$ ), room scale (RS) (beta $=-0.04$ ), property scale (PS) (beta $=-0.27$ ) and business level (BL) (beta $=-0.12$ ) turned out to be significant negative impact factors on resilience. Contrary to our assumptions, this result means that P2PA hosts with more properties/rooms and higher business levels were not as flexible as smaller practitioners in terms of adaptation to the COVID. This finding resonated with the result from control variable host type (HT), where medium operators were fiercely strained in recovery (beta $=-0.50$, ) while single operators and small operators were not as significant. 
Both vulnerability variables, maintenance cost $(\mathrm{MC})$ (beta $=-0.13$ ) and housing burden $(\mathrm{HB})$ (beta $=-0.02$ ) were a significant hindrance to resilience performance. Hosts with higher liability or debt level were more vulnerable in the pandemic and might struggle to make ends meet in maintaining their properties.

Finally, the control variable location type (LT) indicated that hosts with properties in more affluent communities were more likely to recover.

Table 1. Regression model results

\begin{tabular}{|c|c|c|c|c|}
\hline Constructs & Variables & Overall model & Model (Mar-Jun) & $\begin{array}{l}\text { Model (July- } \\
\text { Aug) }\end{array}$ \\
\hline & Constant & $0.02 *(-0.01)$ & $-1.00 * * *(-0.02)$ & $\begin{array}{l}-2.02 * * * \\
(-0.08)\end{array}$ \\
\hline \multirow[t]{2}{*}{ Shock } & Overall shock & $-0.46 * * *(0.00)$ & $\begin{array}{l}-1.98 * * * \\
(-0 \text { n..03) }\end{array}$ & $0.39 * * *(-0.04)$ \\
\hline & Local shock & $0.03 * * *(0.00)$ & $0.05 * *(-0.02)$ & $0.03 * * *(0.00)$ \\
\hline \multirow[t]{4}{*}{ Adaptability } & Host experience & $-0.08 * * *(0.00)$ & $-0.08 * * *(0.00)$ & $\begin{array}{l}-0.07 * * * \\
(-0.01)\end{array}$ \\
\hline & Room scale & $-0.06 * * *(0.00)$ & $-0.06 * * *(0.00)$ & $\begin{array}{l}-0.19 * * * \\
(-0.02)\end{array}$ \\
\hline & Property scale & $\begin{array}{l}-0.10 * * * \\
(-0.02)\end{array}$ & $-0.10 * * *(-0.02)$ & $-0.02(-0.02)$ \\
\hline & Business level & $-0.12 * * *(0.00)$ & $0.01 * * *(0.00)$ & $\begin{array}{l}-0.38 * * * \\
(-0.01)\end{array}$ \\
\hline \multirow[t]{2}{*}{ Vulnerability } & Maintenance cost & $\begin{array}{l}-0.13 * * * \\
(-0.01)\end{array}$ & $-0.11 * * *(-0.01)$ & $\begin{array}{l}-0.17 * * * \\
(-0.02)\end{array}$ \\
\hline & Housing burden & $-0.02 * * *(0.00)$ & $-0.03 * * *(0.00)$ & $0.0037(-0.01)$ \\
\hline \multirow{6}{*}{$\begin{array}{l}\text { Social } \\
\text { superiority }\end{array}$} & Host type [Single] & $0.01(-0.01)$ & $-0.08 * * *(-0.01)$ & $1.00 * * *(-0.04)$ \\
\hline & Host type [Small] & $0.01(-0.01)$ & $-0.08 * * *(-0.01)$ & $0.63 * * *(-0.04)$ \\
\hline & $\begin{array}{l}\text { Host type } \\
\text { [Medium] }\end{array}$ & $\begin{array}{l}-0.50 * * * \\
(-0.01)\end{array}$ & $-0.34 * * *(-0.02)$ & $0.23 * * *(-0.03)$ \\
\hline & Location type & $0.07 * * *(-0.01)$ & $0.06 * * *(-0.01)$ & $0.08 * * *(-0.02)$ \\
\hline & Adjusted R-square & 0.24 & 0.17 & 0.26 \\
\hline & Observations & 112597 & 68354 & 30350 \\
\hline
\end{tabular}

Dependent Variable: Deviated Monthly Revenue

Standard errors in parentheses

$* \mathrm{p}<0.1, * * \mathrm{p}<0.05, * * * \mathrm{p}<0.01$

\section{Discussions, Limitations and Future Directions}

Linking back to our proposed resilience model, the following constructs agreed with our assumptions: 1) vulnerability negatively associates with the resilience of revenue. Housing Burden (HB) turns out to be a valid indicator to examine vulnerability of 
households. 2) the level of overall shock exhibits a negative relationship with the resilience of revenue, while the county-level local shock shows a positive relationship. This interesting paradox may be explained by spatial heterogeneity. This indicates the existence of spatial variances in the P2PA resilience at a regional level. Adopting a spatial approach can help explain the pattern of local variance in resilience.

Two of the constructs exhibit different results compared with our assumptions: 3) adaptability shows a negative association with resilience. Using host experience (HE) to represent hosts' resourcefulness in dealing with crisis may be reasonable, but the statistical results remind us that there could be disturbance when using HE. The longer experience a host has, the higher odds that the P2PA investment as their major income. Such over-dependency on tourism-related industry has leveraged hosts' financial vulnerability. 4) Social superiority shows negative associations with resilience. This can be explained by the hosts' level of dependency on P2PA business. In addition, owning more P2PA properties during a crisis can cut short the cash flow of a host, thus reduce hosts' marketing and operational budget. This may be the cause for the downshift of revenue among those hosts with higher social superiority.

When faced with the threat of COVID outbreaks, P2PA operators should maintain an appropriate level of financial flexibility. We suggest the government and industrial organizations to distinguish the types of P2PA operators when carrying out rescue plans for the P2PA industry. The periodic outbreak and remission of COVID indicates the necessity to examine the pattern of P2PA hosts' business in a temporal perspective. Models in separate stages have been conducted, yet the results have not been fully addressed in the short paper. Ideally, a lengthened observation timeframe is encouraged to detect temporal patterns with robustness and carry out a potential time-series model. Extended data collection and analysis are expected in the full-paper version to complement current findings.

Theoretically, this paper examined an adapted resilience model and operationalized constructs like adaptability, vulnerability, and shock in different ways in P2PA industry. However, further examinations are needed to improve the reliability of this framework in tourism field.

\section{References}

1. Rivera M, Kizildag M, Croes R (2021) Covid-19 and small lodging establishments: a breakeven calibration analysis (CBA) model. Int J Hosp Manag 94:102814. https://doi.org/10. 1016/j.ijhm.2020.102814

2. Pimm SL (1984) The complexity and stability of ecosystems. Nature 307:321-326. https:// doi.org/10.1038/307321a0

3. Briguglio L, Cordina G, Farrugia N, Vella S (2009) Economic vulnerability and resilience: concepts and measurements. Oxford Dev Stud 37:229-247. https://doi.org/10.1080/ 13600810903089893 
4. Martin R (2012) Regional economic resilience, hysteresis and recessionary shocks. J Econ Geogr 12:1-32. https://doi.org/10.1093/jeg/lbr019

5. Jamal T, Camargo BA (2014) Sustainable tourism, justice and an ethic of care: toward the just destination. J Sustain Tour 22:11-30. https://doi.org/10.1080/09669582.2013.786084

6. Burrai E, Font X, Cochrane J (2015) Destination stakeholders' perceptions of volunteer tourism: an equity theory approach. Int J Tour Res 17:451-459. https://doi.org/10.1002/jtr. 2012

Open Access This chapter is licensed under the terms of the Creative Commons Attribution 4.0 International License (http://creativecommons.org/licenses/by/4.0/), which permits use, sharing, adaptation, distribution and reproduction in any medium or format, as long as you give appropriate credit to the original author(s) and the source, provide a link to the Creative Commons license and indicate if changes were made.

The images or other third party material in this chapter are included in the chapter's Creative Commons license, unless indicated otherwise in a credit line to the material. If material is not included in the chapter's Creative Commons license and your intended use is not permitted by statutory regulation or exceeds the permitted use, you will need to obtain permission directly from the copyright holder.

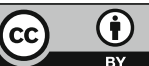

